\title{
Reflection
}

\section{Journal club and post-graduate medical education}

\author{
Surajit Bhattacharya \\ Senior Consultant, Plastic, Reconstructive \& Aesthetic Surgery, Sahara Hospital, Lucknow, India
}

Address for correspondence: Dr. Surajit Bhattacharya, C-907, Mahanagar, Lucknow - 226 006, Uttar Pradesh, India. E-mail: surajitbh@yahoo.co.in

\section{ABSTRACT}

A journal club is an educational meeting in which a group of individuals discuss published articles, to keep themselves abreast of new knowledge, promoting in them the awareness of current research findings, teaching them to critique and appraise research, and encourage them to utilize research in evidence based practice of the speciality. With so much of market driven research in journals the role of journal club becomes even more vital to differentiate a genuine recent advance from a clever but outright harmful rediscovery of the wheel which has been long discarded. Journal clubs can be department initiated or journal initiated and there are randomized control trials to prove that they improve reading habits, knowledge of epidemiology and statistics, and use of medical literature in practice. Choosing the journal club articles, assessing them and presenting them in the journal club meeting are all of vital importance and as a trainee advances in his training he/she is expected to imbibe the best from his seniors and peers in the club. I a journal club one is simply expected to summarize the research question, the methods, the results and the conclusions and not slavishly read through the article. It is the presenter's interpretation that is more important than actually rehashing the contents of the article.

\section{KEY WORDS}

Evidence based practice, journal club, post-Graduate medical education, research critique

journal club is an educational meeting in which a group of individuals discuss published articles, providing a forum for a collective effort to keep up with the current literature. Right from the time in 1877 when Sir William Osler started the first formal journal club for undergraduates at McMaster University, almost all good departments, teaching various branches of Medicine and Surgery, have strived to have a journal club. Sir William originally started with the idea of

\begin{tabular}{|l|l|}
\hline \multicolumn{2}{|c|}{ Access this article online } \\
\hline Quick Response Code: & Website: \\
\hline & www.ijps.org \\
\cline { 2 - 2 } & Dol: \\
\hline
\end{tabular}

facilitating the distribution of unaffordable periodicals and later evolved it into a book and journal club that met over dinner to review the latest in medical research. He wanted that the journal club should 'afford opportunities, which after graduating you never obtain, of learning how to prepare papers and express your ideas correctly'. He also hoped the meetings would secure 'training in the difficult science of debate'. [1] These objectives of promoting the discussion and

This is an open access article distributed under the terms of the Creative Commons Attribution-NonCommercial-ShareAlike 3.0 License, which allows others to remix, tweak, and build upon the work non-commercially, as long as the author is credited and the new creations are licensed under the identical terms.

For reprints contact: reprints@medknow.com

How to cite this article: Bhattacharya S. Journal club and postgraduate medical education. Indian J Plast Surg 2017;50:302-5. 
critique of research remain largely the essence of every journal club even today.

There is a huge potential to make journal clubs dynamic, modern and interactive, keeping them alive by dispelling outdated perceptions of sleeping juniors attending under duress and confused seniors presenting stuff they themselves are not clear about. Journal clubs help the post-graduates in keeping abreast of new knowledge, promoting awareness of current research findings, learning to critique and appraise research and encouraging utilisation of research in practice..$^{[2,3]}$ They, therefore, improve knowledge and reading habits while keeping the momentum of medical knowledge going and creating enthusiasm for research. With the regular didactic sessions, formal assessments or integrated evidence-based medicine teaching hardly challenging this repertoire, journal clubs remain essential in post-graduate medical education.

\section{THE MAKING OF A RESEARCH CRITIQUE}

Evaluating research for utilisation in clinical practice involves more than simply reading research but debating it, analysing it and understanding its $360^{\circ}$ implications and outcomes. The overall goal of a research critique is to formulate a general evaluation of the merits of a study and to evaluate its applicability to clinical practice. A research critique goes beyond a review or summary of a study and carefully appraises a study's strengths and limitations. The critique should reflect an objective assessment of a study's validity and significance. A research study can be evaluated using its component parts and a thorough research critique examines all aspects of a research study.

\section{JOURNAL CLUB AND EVIDENCE-BASED MEDICINE}

Evidence-based medicine is defined as the "conscientious, explicit and judicious use of the current best evidence in making decisions about the care of individual patients'. ${ }^{[4]}$ The alternative to this is 'I do as I wish' or whim-based medicine, or I do as my teacher does or eminence-based medicine, and they both are neither standardised nor cost-effective and certainly not reproducible and often pathetically indefensible in the court of law. Adherence to evidence-based practice requires up-to-date knowledge and a sound understanding of critical appraisal to navigate the minefield of medical literature which adds on every day at alarming proportions. Unfortunately, doctors often begin clinical life deficient in these skills as these skills are not taught to them in medical schools. A journal club fills in this gap of knowledge and helps one practise evidence-based medicine in future.

\section{PROVING THE IMPACT OF JOURNAL CLUBS}

The first randomised controlled trial looking at the impact of journal clubs on knowledge and the critical appraisal was done in 1988. Medical interns received either journal club teaching or a series of seminars. Nearly $86 \%$ of the journal club group reported improvements in their reading habits compared with $0 \%$ in the control group. Journal club participants also obtained greater knowledge scores. ${ }^{[5]}$ Journal clubs were found to improve reading habits, knowledge of epidemiology and statistics and use of medical literature in practice. It facilitated an interest in research and this, in turn, fuelled evidence-based medicine and provision of a medium that stimulated discussion and debate.

\section{JOURNALS INITIATING A JOURNAL CLUB}

Journal clubs can be face to face or online. They cannot be one size fits all type. They have to be tailored to the speciality and to the career level of the participants. Hence, in plastic surgery, it may involve taking emphasis away from statistics and epidemiology towards the clinical query and finer details of technique. Journals and periodicals are now coming out with special journal club articles. The American Journal of Critical Care has the $A J C C$ Journal Club and each issue of the journal featured an $A J C C$ Journal Club article with a website link that provided questions and discussion points to stimulate a journal club discussion in which participants can evaluate new research and its applicability to clinical practice. ${ }^{[6]}$. PRS has too initiated a journal club. ${ }^{[7]}$ With each issue of PRS one can read 3 discussion-worthy articles, each paired with classic papers and videos; Listen to podcasts featuring special guests and Resident Ambassadors; and Discuss with the authors live via \#PRSJournalClub for further discussions in Journal Clubs around the country, on Twitter, and in the PRS Journal Club Podcasts. The chosen articles are marked with a "Journal Club" icon. It would be nice if the Indian Journal of Plastic Surgery can start this practice, publish a journal club article followed by a list of discussion points to stimulate a journal club discussion in which participants can evaluate new 
research and its applicability to clinical practice. This will be a big help for the teaching departments.

\section{DEPARTMENTS STARTING A JOURNAL CLUB}

The teaching department themselves can start their own journal clubs ${ }^{[6]}$ if they do not have one by:

1. Posting and distributing copies of the research article and the journal club discussion questions to the post-graduate students

2. Set up a convenient meeting time and location

3. Identify a facilitator for the meeting, which will depend on the sub-speciality papers being discussed. A craniofacial surgeon will perhaps not do justice to a hypospadias article

4. Hold the journal club and encourage active participation of those attending using the discussion questions

5. Evaluate the journal club by gathering feedback from participants at the end of the meeting

6. Determine how the next journal club meeting could be made more beneficial, for example, encourage more allied faculty attendance, add breakfast/lunch to the schedule, tape-record the session for those unable to attend

7. Schedule the next meeting.

If the attendees find that the time spent at journal club meetings is productive, there will be no problems in continuing with it.

\section{CHOOSING THE JOURNAL CLUB ARTICLES}

Choosing a journal club article would be equally important. I will offer some standard guidelines:

1. Choose a good journal with a very high rejection rate. The New England Journal of Medicine has a rejection rate of over $90 \%$, thus ensuring the scientific merit of its papers. PRS, JPRAS and IJPS have all high rejection rates and usually have good papers

2. Look at the name of the institution, as a rule, good papers tend to come from good institutions as they do not let sub-standard research go out for peer review. It is less likely that good hard science will come from an unknown institution

3. Look at the author's name, you may know the author and his/her veracity. Good authors are conscious about their reputation and do not lend their name to substandard research
4. Look at the bottom of the first page or the end note of the paper for grant support. A paper which has received ICMR or NIH funding, probably had, at its inception, had a strong proposal and the senior author enjoys the faith of prestigious organisations such as ICMR or NIH

5. Immediately below the author names, there is often a note about whether this paper was awarded by an organisation or presented at an international meeting. An award paper from APSI or BAPS will invariably be a good one. A paper accepted for podium presentation at an international conference passes through strict scrutiny and is often the chosen one

6. Look at the dates of submission and acceptance - if the gap is small, this is a good paper which obtained the nod of the reviewers and got accepted without revisions. As against it, a long gap means multiple revisions

7. Many journals have articles for the forthcoming issue on their website, and so the paper and letters to the editor in response to it can appear in the same issue. PRS articles often lose their sheen if letters attacking the core of the article appear at the back!

\section{ASSESSING A RESEARCH PAPER}

Assessing a research paper is also an art the post-graduates should learn. The abstract is very important part of the paper because a good abstract conveys the gist of the research unambiguously-what was the research question, how was the study planned to address the question, what was observed and what all was concluded from those observations, and finally was the research question answered? The introduction should be able to convey the research question, the objective or the hypothesis. The material and method should be vivid and reproducible and clear. If there was a control group, it should be clearly studied. The observations should be stated in an unbiased manner, and no attempt should be made to overinterpret it in the results. Statistics should be to state the obvious and not confuse the readers. Appropriate statistics and appropriate power calculations should ensure that a given study group size is statistically appropriate. The discussion is vital for the journal club because it usually provides fodder for discussion. Papers which rely on a simple phenomenon of nature like the duskiness of a skin flap, without explaining the mechanism clearly, like in this case interpreting the duskiness as venous obstruction without ruling out other possibilities should be brought 
out in the journal club discussion. Experimental articles should be scrutinised for their experimental designs and failings.

\section{PRESENTATION IN A JOURNAL CLUB}

While presenting the paper in a journal club, one has to be concise, review the article in one's own words in 5 min because everyone else has a copy and has read it at leisure. One is simply expected to summarise the research question, the methods, the results and the conclusions and not slavishly read through the article. In a journal club, the presenter's interpretation is more important than actually rehashing the contents of the article.

All this teaches a post-graduate how to do high-quality research, how to critically analyse research data, how to understand the finer points of surgical technique and how to avoid research and clinical pitfalls. Landmark papers like 'The vascular territories (angiosomes) of the body' published in BJPS by Taylor and Palmer in 1987 is still a great paper for a journal club simply because it teaches a post-graduate how to plan, design and conduct a monumental research!

\section{SUMMARY}

A journal club serves three purposes: teach and develop critical appraisal skills, increase exposure to rapidly evolving medical literature and help in informed clinical practice. They facilitate better knowledge and literature awareness through group discussion with peers. They provide a unique opportunity to promote interest in research while learning from experts about knowledge gaps and future research questions.

\section{Financial support and sponsorship}

Nil.

\section{Conflicts of interest}

There are no conflicts of interest.

\section{REFERENCES}

1. Cushing H. The Life of Sir William Osler. Vol. 1. Oxford At The Clarendon Press 1925. p. 154.

2. Ebbert JO, Montori VM, Schultz HJ. The journal club in postgraduate medical education: A systematic review. Med Teach 2001;23:455-61.

3. Harris J, Kearley K, Heneghan C, Meats E, Roberts N, Perera R, et al. Are journal clubs effective in supporting evidence-based decision making? A systematic review. BEME guide no 16. Med Teach 2011;33:9-23.

4. Sackett DL, Rosenberg WM, Gray JA, Haynes RB, Richardson WS. Evidence based medicine: What it is and what it isn't. BMJ 1996;312:71-2.

5. Linzer M, Brown JT, Frazier LM, DeLong ER, Siegel WC. Impact of a medical journal club on house-staff reading habits, knowledge, and critical appraisal skills. A randomized control trial. JAMA 1988;260:2537-41.

6. What is a Journal Club? - American Journal of Critical Care. Available from: http://www.ajcc.aacnjournals.org/site/misc/ journalclubwebpage.pdf. [Last accessed 2017 Jun 08].

7. http://journals.Iww.com/plasreconsurg/Pages/ PRS-Journal-Club-.aspx

8. Taylor GI, Palmer JH. The vascular territories (angiosomes) of the body: Experimental study and clinical applications. Br J Plast Surg 1987;40:113-41. 